\title{
Cultural Values, Religion and Psychosis: Five Short Stories
}

\author{
Michael TH Wong, Fiona Wilson, Dennisa Davidson, \\ Caitlin Hick, and Andrew Howie
}

\subsection{Introduction}

Culture and spirituality constrain the way we see our world in ways that sometimes become apparent only when challenged. The issue is more complex still when psychosis and serious mental illness are assessed in the context of spiritual and cultural difference. The following five case narratives-written from different perspectives-illustrate different aspects of these constraints and complexities.

Case Narratives Note: Case narratives one to three are a synthesis and fictional reworking of a number of patient cases and are completely de-identified. Narrative four is based on that of a real person but the name and other identifying details have been changed to protect confidentiality. Narrative five is autobiographical and by a member of the author team.

\footnotetext{
M. TH. Wong $(\triangle)$

Department of Psychiatry, Li Ka Shing Faculty of Medicine, The University of Hong Kong,

Hong Kong, China

e-mail: mthwong@hku.hk

F. Wilson

Manaaki House Community Mental Health Centre, Auckland District Health Board,

Auckland, New Zealand

e-mail: fionawilson@xtra.co.nz

D. Davidson

"Taunaki" Child and Adolescent Mental Health Service, Counties Manukau District Health

Board, Auckland, New Zealand

e-mail: dennisadavidson@yahoo.co.nz

C. Hick

North Tec, Whangarei, New Zealand

e-mail: loulou.14069@gmail.com
}
A. Howie
Whitiki Maurea Maori Mental Health and Addiction Service, Waitemata District Health
Board, Auckland, New Zealand
e-mail: ajshowie@gmail.com
(C) The Author(s) 2021
D. Stoyanov et al. (eds.), International Perspectives in Values-Based Mental
Health Practice, https://doi.org/10.1007/978-3-030-47852-0_14 


\subsection{Case Narrative One}

"Robert" is a 23-year-old single unemployed New Zealand European male who lives with his parents. His family are committed Church-going Christians of a Pentecostal denomination. Pre-morbidly, Robert was very sociable and academically was a high achiever. While Robert was attending tertiary education, his family became concerned as he had a decline in academic performance, poor self-care and preoccupation with religious beliefs and they contacted mental health services. Robert was hostile and uncooperative with assessment. His parents confirmed that he had reported hearing the voices of God and the Devil for at least a year and explained that was not considered unusual in their Church Community.

Robert was diagnosed with Schizophrenia, paranoid type. He repudiated the diagnosis, continued to be hostile towards mental health services and was nonadherent to prescribed medication. This resulted in a number of admissions to the local mental health unit. Prior to his last admission, Robert had again discontinued his prescribed oral medication, was disorganized and neglected in his presentation and was preoccupied with the belief that he had caused the deaths of a number of people by praying for God to pass judgement on them via an influenza epidemic. He was discharged from hospital on a compulsory treatment order under the Mental Health Act and prescribed depot antipsychotic medication. The treatment resulted in some amelioration of his presentation but he did not return to his pre-morbid level of functioning.

Robert continued to report experiences of hearing the voices of God and the Devil and denied that the prescribed medication had any impact on his experiences. One of the clinical psychologists in the mental health team espoused Christian beliefs and offered to work with Robert; however, Robert declined this. He also declined referral to the mental health chaplain.

On one occasion Robert came to his psychiatry appointment with a collection of his writings. These writings consisted of copied Biblical texts. He said that God had instructed him to read to the psychiatrist. He was focused on a text concerning "Love your enemies" and believed that God had told him to change his attitude towards the mental health staff.

\subsection{Case Narrative Two}

"Aroha" is a 30-year-old New Zealand Māori woman who strongly identifies with her Māori culture. She is unemployed and lives with her male partner in a relationship of several years' duration. She has no children. Aroha is one of a number of siblings, all of whom were exposed to physical, emotional and sexual abuse as children and were removed from their parents' care into state custody. Their foster care was unstable and they experienced multiple caregivers over time. Most of the siblings were separated but Aroha and her twin brother, "Anaru”, were placed together. Aroha and Anaru had a very close bond. 
In her early twenties, Aroha was diagnosed with Schizoaffective disorder and was treated with anti-psychotic medication. The differential diagnosis was complex Post Traumatic Stress Disorder. She had good engagement with her treating team and had a period of successful psychological treatment. She presented with a marked deterioration in her mental state following Anaru's sudden death in a single vehicle motor crash in another town. She was unable to sleep, distressed and disorganised and had persecutory delusional beliefs that gang members wanted to kill her. She also reported seeing the ghost of her deceased brother, whom she reported was in distress.

Aroha was treated at home with increased support from mental health services and her medication was optimised. In addition, an urgent referral was made to a kaumatua (Māori elder with spiritual authority) under the auspices of mental health services as it is known that Māori may see visions of deceased whānau (family) following their death. The kaumatua advised that Aroha should return to her marae in another town to see the kaumatua there in order to have the appropriate karakia (prayers) and ritual to ensure that her brother's spirit passed peacefully on to the spirit world. (Māori believe that the spirits of the deceased travel to Cape Reinga, northern most part of Aotearoa New Zealand to leave for their ancestral home of Hawaiki). Aroha followed this advice which led to some resolution of her level of distress. She and her partner then moved back to her home town and follow-up was arranged with the appropriate service.

\subsection{Case Narrative Three}

"John” was a single 25-year-old New Zealand European male living with his parents. He had attained a University degree and was working full time in a responsible position. His family was not religious but as a teenager John had become a committed Christian which was the focus of his life. Also, in his late teenage years, John was diagnosed with Bipolar Affective Disorder. He had three inpatient admissions with mania and psychosis and was treated with Lithium. While adherent to prescribed treatment, he had complete inter-episode recovery with return to full employment.

However, because he had been well for 3 years, he became convinced that he no longer needed pharmacological treatment and slowly discontinued his medication over several months. Unfortunately, this led to a major relapse of mania and psychosis with erratic and disinhibited behaviour at his place of employment and loud, disorganised preaching at his Church. His behaviour was witnessed by many people, and led to hospitalisation and dismissal from his employment.

His mental state had improved such that he was no longer psychotic or manic but he was in danger of becoming depressed as he faced up to the toll that his behaviour, when unwell, had taken on his relationships and employment. He felt that his life was ruined and felt too ashamed to return to his Church. He said that he had no one to talk with except the psychiatrist. He asked the psychiatrist whether they shared any religious beliefs. At that time, the Psychiatrist believed that it was in the 
best interest of the patient to disclose that they came from a similar religious background without divulging any further information [1]. John then felt comfortable to talk about his religious beliefs.

The psychiatrist was familiar with "Spiritually Augmented Cognitive Behaviour Therapy" [2] which includes encouraging patients to re-engage with their spirituality. With John's permission, the psychiatrist contacted his church minister and a meeting was arranged to discuss how John could re-engage with the church. One of the Peer Support Workers in the mental health team attended the same church as John and undertook to support him with his return to church. A few weeks later, John was happy to report that he had indeed returned to church and was regularly engaged in worship and a small group for prayer and Bible study. He had been uplifted by a Biblical text given to him by a church member: Romans 8:28 "We know that all things work together for good for those who love God, who are called according to his purpose." His mood was euthymic and he was soon able to secure new employment. He was committed to continue taking his prescribed Lithium, seeing that as part of God's plan for his life.

\subsection{Case Narrative Four}

The clinician was mid-way in her specialist training when "Richard", a 70 years old widower was admitted to the older-people's inpatient unit following attempting to jump off a highrise building.

Richard had no history of mental illness. Neither was he new to adversity. He had lived through his home being destroyed by a storm and the passing of his wife after a rather brief illness in midlife. He had survived cancer 2 years ago and had moved to a new city to start a new life. Within months after the move, the cancer recurred, leaving him with few options that he chose to decline. He felt an overwhelming sense of futility, loneliness and being let down-Let down by his deceased wife, for whom he had been there till the end, who could not be with him now when his own days were measured. Let down by his children who were too far away in his time of emotional need. Let down by the doctors whom he believed had promised the cancer will not return. Let down by God, whom he had known better in earlier years yet in whom he retained a sense of omnipotence.

He was trialled on a number of medication regimes. Therapists tried hard to engage him. His children came over to visit. The only unwavering response was a stoic withdrawal.

Eventually, after discussing with her supervisor, the trainee psychiatrist gave a copy of the lyrics of the song, 'Precious Lord, take my hand' to the staff to pass on to Richard if he showed interest. Staff laminated it and passed it on to the chaplain who gave it to him. He accepted this and started to come out to participate in the weekly chapel service held in the unit, first sitting at the periphery before slowly engaging more. He went on to engage with other therapies and his family and was discharged much improved. He was reported to continue his spiritual journey post-discharge. 


\subsection{Case Narrative Five}

Case Narrative Five is an autobiographical account of a 17-year-old New Zealand European woman's illness journey. She has called her story "Mental Health with God".

My journey through teenagehood was no walk in the park. I had suffered with Anorexia Nervosa, depression and severe anxiety that had all stemmed from a traumatic childhood. I have believed in God for as long as I can remember, which is kind of strange since none of my family members believe. In fact, my Dad is a proud atheist so when I began to start having serious issues at 14 years of age, I could not relate or talk to my parents about it all.

Without my faith I would have died the first time I tried to take my own life. Some people tell me that God and religion are a crutch just like people use drugs and drink, etc. But I can tell you that it's nothing like that. I found truth about myself out of hard times, knowing that I was loved and cared for, that I was made for a divine purpose and that all of what broke me was not for nothing.

My faith is the backbone of my resilience and the foundation of my present growing self-love. In times where I have been overwhelmed with fear and anxiety, there are verses I can turn to in the Bible that are not just comforting but they ring true in situations from my past as well; and this brings me a lot of resolution.

It's not just a belief, it's a relationship. Unlike coping skills given by my support team, the relationship I have with God helps me on a personal level and it's never something I can overuse. When things are getting difficult again, God is prepared to help me in a way that is intricate and personalised to my exact needs. It doesn't happen like clockwork though and sometimes He comes through for me in the words from other people or even in songs. God doesn't work like an instruction manual either. In all of these battles I have fought, God's love for me is interlaced into everything I have been through.

God working in my life is just having an ever-present father figure or a friend, and I truly feel loved and understood through the things I have learned over the years.

\subsection{Values and Cultural Issues Arising}

The above five case narratives highlight the various challenges facing the mental health system in New Zealand arising out of the cross-cultural interaction of a number of values between Anglo-European religion, Maori spirituality and secular psychiatry.

First, the underlying historical-political values. Aotearoa New Zealand is a nation shaped by the Treaty of Waitangi signed in 1840 by the British Crown and many of the Māori tribes of Aotearoa New Zealand. The treaty continues as the foundation for Māori in having a partnership with the government for their protection, participation in decisions that impact their well-being and among the 
articles of the treaty, the rights to cultural practices and freedom of religious beliefs.

Second, the values of immigrants. From the twentieth century onwards, there have been waves of migration to New Zealand from many lands, leading to a rich diversity of cultures, languages and beliefs.

Third, the values of the professionals. In 2018, the RANZCP adopted a Position statement on Psychiatry and Religion/Spirituality [3]. Thus far, there is no specific training for Psychiatrists in this area and a paucity of research in Aotearoa New Zealand. Psychiatrists in New Zealand are Fellows or Affiliates of the Royal Australian and New Zealand College of Psychiatrists (RANZCP), and they are a culturally diverse group.

Fourth, the values of the Māori. Mason Durie's model [4] emphasises that any attempt to separate wairua (spiritual) and whanau (extended family) issues from consideration of well-being will fail for Māori, possibly to an overwhelming degree.

The interaction of these four values is now discussed further through the five case narratives.

The narrative of "Robert" illustrates the challenges of integrating appropriate mental health care and spirituality in a patient who has been diagnosed with a psychotic illness, involving auditory hallucinations and delusions of a religious nature. His lack of insight and persistent hostility towards the treating team poses a major difficulty which the latter tackle by trying to steer a middle course of validating what are appropriate beliefs to the religious persuasion of Robert and continuing treatment with antipsychotic medication to enable him to function adequately in the community. This seems to have worked, and Robert eventually develops a therapeutic relationship with his treating team which supports and helps him stay stable despite remaining symptomatic.

The illness experience of "Aroha" highlights the importance of spiritual and cultural assessment and interventions in a patient who has both a diagnosis of a psychotic illness and an acute spiritual problem. It is recognized that psychiatrists can over-diagnose psychosis in patients who belong to different cultures from their own. In Aotearoa New Zealand, the Treaty of Waitangi documents the partnership between the Government and Māori iwi (tribes) to ensure the protection of their rights. Professor Sir Mason Durie (a Māori Psychiatrist) has developed a Māori model of health, "te whare tapa wha" - a house with four posts, a model that is disseminated widely within Aotearoa New Zealand:

- Taha Tinana (Physical health)

- Taha Hinengaro (Mental health)

- Taha Whānau (Extended Family health)

- Taha Wairua (Spiritual health)

This Māori model of health addresses the enormous impact of colonization on indigenous cultures - spirit-breaking - which has affected multiple generations in areas such as physical and mental health, education, employment and family relationships leading to disconnection from language, culture and land. For "Aroha," 
this model allows a reconnection with the Māori spiritual understanding of death and the ritual of bereavement, bringing about a resolution of grief and distress and promoting a remission of her psychotic illness.

The psychotic breakdown of "John" and the associated behavioural disturbance not only result in loss of employment and disruption of relationships but also lead to shame, spiritual despair, and self-imposed social isolation. Through the support of his treating team who is sensitive to his spiritual needs, John manages to achieve a good remission, re-engage with his church community and return to the workforce. The narrative of John shows how religion and spirituality are important aspects of patients' illness experience and recovery journey and can have a role in resilience for patients with severe mental illness. While "John" and "Aroha" belong to different ethnic, cultural and religion traditions, they both have benefited from a holistic model of service delivery that covers biological, psychological, cultural and religious/spiritual aspects of care.

"Richard" has given up and as each therapeutic intervention fails, he has become more "set" in his giving up. Spirituality was one of the few interventions that remain. The trainee psychiatrist feels this may be beneficial but struggles with how to approach this. When this is addressed, it seems to awaken in him a renewed sense of meaning and purpose in life and a sense of being cared for by Someone and not being alone. The narrative of Richard represents challenges at end of life and suggests that spirituality may be an appropriate adjunct to offer in therapy [5].

The autobiographical account in Case Narrative Five gives us a glimpse of the traumatic childhood, severe anxiety, eating issues, emotional dysregulation and suicidal ideation of a 17-year-old girl and how her faith has sustained her. Her story of "Mental Health with God" reminds us that spiritual and religious beliefs, and in her case, the Christian Faith remains a source of hope, strength, love, healing and a means to express meaning, significance and sense of well-being for some people [6,7]. This is despite the fact that the world we live in is increasingly secular and that it is getting difficult all the time for both patients and mental health professionals to speak and discuss spiritual issues with ease and feel safe and comfortable to do so. The latest statistics from New Zealand show that almost half the population see themselves as of "no religion" [8]. It is possible that at times, Christianity may even be perceived as a vestige of colonialism than a personal relationship with God.

\subsection{Conclusion}

Anglo-European religion, Māori spirituality and secular psychiatry in New Zealand continue to form a complex and dynamic web which is still being woven out with cultural, spiritual and cultural tension.

The particular case of psychosis and serious mental illness discussed here through five case narratives highlights that the experience, expression and perception of psychosis and serious mental illness as well as their diagnosis, treatment, 
recovery and rehabilitation require a holistic approach that involves not only biological intervention but also psychosocial support and spiritual healing.

Within this clinical framework of values and culture, health and well-being in patients living with psychosis and serious mental illness are not adequately represented only by the control of symptoms or containment of difficult behaviour. Instead, mental health and well-being take on a new perspective of meaning and significance which draws from the cultural heritage and religious tradition of the patients through which fragmented identity is rebuilt, lost roles regained and alienated relationships reconnected.

The five short stories narrated here remind us that culture, religion and spirituality continue to play an important role in the practice of psychiatry in our increasingly secular contemporary world.

Acknowledgements The idea of this article originates from a symposium the authors organized at the Royal Australian and New Zealand College of Psychiatrists 2018 Congress held on May 17-21 in Auckland, New Zealand. We appreciate the critical and constructive comments from the participants who include patients, carers, hospital chaplains, allied mental health workers, nurses, psychologists and psychiatrists from New Zealand, Australia, Asia and the Pacific Islands.

\subsection{Guide to Further Sources}

Royal Australian and New Zealand College of Psychiatrists. Position Statement PS 96, June 2018. The relevance of religion and spirituality to psychiatric practice. https://www.ranzcp.org/news-policy/policy-and-advocacy/position-statements/ the-relevance-of-religion-and-spirituality-to-psyc

WPA Position Statement on Spirituality and Religion in Psychiatry. https://www. seminare-ps.net/positionspapiere/WPA_Statement_Rel_Psychiatry.pdf

Royal College of Psychiatrists. Position Statement PS03/2013, November 2013. Recommendations for psychiatrists on spirituality and religion. https://www. rcpsych.ac.uk/pdf/PS03_2013.pdf

\section{References}

1. Florence H. Deciding what belongs: how Psychotherapists in Aotearoa New Zealand attend to Religion and/or Spirituality. PhD Thesis. Auckland University of Technology; 2015.

2. D’Souza R. Spiritually augmented CBT. Australas Psychiatry. 2004;12(2):148-52.

3. https://www.ranzcp.org/news-policy/policy-and-advocacy/position-statements/ the-relevance-of-religion-and-spirituality-to-psyc

4. Durie M. Whaiora: Māori health development. Auckland: Oxford University Press; 1998. p. 68-74.

5. Breitbart W, Gibson CA, Poppito SR, Berg AL. Psychotherapeutic interventions at the end of life: a focus on meaning and spirituality. Can J Psychiatry. 2004;49(6):366-72. 
6. Wong YJ, Rew L, Slaikeu KD. A systematic review of recent research on adolescent religiosity/spirituality and mental health. Issues Ment Health Nurs. 2006;27(2):161-83.

7. Chang-Ho CJ, Perry T, Clarke-Pine D. Considering personal religiosity in adolescent delinquency: the role of depression, suicidal ideation, and church guideline. J Psychol Christ. 2011;30(1):3-15.

8. http://worldpopulationreview.com/countries/new-zealand-population/

Open Access This chapter is licensed under the terms of the Creative Commons Attribution 4.0 International License (http://creativecommons.org/licenses/by/4.0/), which permits use, sharing, adaptation, distribution and reproduction in any medium or format, as long as you give appropriate credit to the original author(s) and the source, provide a link to the Creative Commons license and indicate if changes were made.

The images or other third party material in this chapter are included in the chapter's Creative Commons license, unless indicated otherwise in a credit line to the material. If material is not included in the chapter's Creative Commons license and your intended use is not permitted by statutory regulation or exceeds the permitted use, you will need to obtain permission directly from the copyright holder.

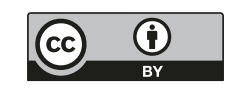

